\title{
The Transcriptional Activator rfiA \\ Is Quorum-Sensing Regulated by Cotranscription with the Iuxl Homolog pcol and Is Essential for Plant Virulence in Pseudomonas corrugata
}

\author{
Grazia Licciardello, ${ }^{1,2}$ Iris Bertani, ${ }^{3}$ Laura Steindler, ${ }^{3}$ Patrizia Bella, ${ }^{2}$ Vittorio Venturi, ${ }^{3}$ and \\ Vittoria Catara ${ }^{2}$ \\ ${ }^{1}$ Science and Technology Park of Sicily, Catania, Italy; ${ }^{2}$ Department of Phytosanitary Science and Technologies, University \\ of Catania, Italy; and ${ }^{3}$ Bacteriology Group, International Centre for Genetic Engineering and Biotechnology, Area Science \\ Park, Padriciano, Trieste, Italy
}

Submitted 15 March 2009. Accepted 10 August 2009.

\begin{abstract}
The gram-negative phytopathogen Pseudomonas corrugata has an acyl-homoserine lactone (AHL) quorum-sensing (QS) system called PcoI/PcoR that is involved in virulence on tomato. This work identifies, downstream of pcoI, a gene designated $r f i A$, which we demonstrate is directly linked to QS by cotranscription with $p c o I$. The deduced RfiA protein contains a DNA-binding domain characteristic of the LuxR family but lacks the autoinducer-binding terminus characteristic of the QS LuxR-family proteins. We also identified, downstream of $r f i A$, an operon designated pcoABC, encoding for the three components of a tripartite resistance nodulation-cell-division (RND) transporter system. The expression of pcoABC is regulated by RfiA. We found that lipodepsipeptide (LDP) production is cell density dependent and mutants of pcoI, pcoR, and $r f i A$ are unable to inhibit the growth of the LDP-sensitive microorganisms Rhodotorula pilimanae and Bacillus megaterium. $P$. corrugata rfiA mutants were significantly reduced in their ability to cause necrosis development in tomato pith. In addition, it was established that PcoR in the absence of AHL also played a role in virulence on tomato. A model for the role of PcoI, PcoR, and RfiA in tomato pith necrosis is presented.
\end{abstract}

Pseudomonas corrugata (Roberts and Scarlett 1981 emend. Sutra et al. 1997) is a ubiquitous bacterium isolated from a wide variety of sources (Catara 2007). It was first described by Scarlett and associates (1978) as the causal agent of tomato pith necrosis (TPN) and was later isolated in association with TPN in all the tomato-growing areas of the world. P. corrugata has also been identified occasionally as causal agent of pepper pith necrosis (Lopez et al. 1988) and has been reported once in chrysanthemum (Fiori 1992) and geranium (Magyarosy and Buchanan 1995). The characteristic symptom of the disease is stem pith necrosis; the pith may appear as necrotic and frequently disaggregated in the core. The disease is commonly observed in the field and greenhouse where conditions seem

The nucleotide sequence data is available in the GenBank/EMBL/DDBJ database under accession number EF189721.

Corresponding author: V. Catara; E-mail: vcatara@unict.it

* The $e$-Xtra logo stands for "electronic extra" and indicates that Figure 4 appears in color online. more favorable: free water on leaves and stem surfaces and high soil nitrogen levels, which lead to more tender vegetation, promote $P$. corrugata infection (Carroll et al. 1992; Naumann et al. 1989; Scarlett et al. 1978). P. corrugata has been isolated from nondiseased plants, mainly as an endophyte from the rhizosphere, and has also been recovered from bulk soil (Catara 2007). Interestingly, $P$. corrugata has an antimicrobial activity in vitro against a large number of microorganisms (including gram-negative and gram-positive bacteria, Chromista, yeast, and fungi) and has been successfully tested as a biological control agent against plant pathogens in different pathosystems (Catara 2007; Choi et al. 2003; Schmidt et al. 2004; Zhou and Paulitz 1993).

P. corrugata produces the phytotoxic and antimicrobial cationic lipodepsipeptides (LDP), corpetin A and corpeptin B, and the lipodepsinonapeptide cormycin A, which are thought to act as major virulence factors (Emanuele et al. 1998; Scaloni et al. 2004). P. corrugata has also been reported as producing alginate (Fett et al. 1996) and a siderophore, corrugatin, which could be involved in pathogenicity and colonization (Risse et al. 1998). Antimicrobial activity is probably a result of the production of LDP (Emanuele et al. 1998; Scaloni et al. 2004) and other substances such as inhibitory volatiles (Fernando et al. 2005), hydrogen cyanide (Ramette et al. 2003), and pyrrolnitrin (Garbeva et al. 2004).

Recently, we demonstrated that quorum sensing (QS) is intimately linked to $P$. corrugata virulence (Licciardello et al. 2007). QS allows bacterial populations to coordinate the expression of some traits in a cell-density-dependent manner and relies on the production and response to signal molecules (Fuqua et al. 1994). $N$-acyl homoserine lactones (AHL) are most commonly used as QS signal molecules in gram-negative bacteria (Fuqua and Greenberg 2002). The paradigm of the production and response to AHL is the Vibrio fischeri LuxI/R system, consisting of an AHL synthase member of the LuxI family and a transcriptional regulator belonging to the LuxR family. As the density of the population increases, so does the concentration of AHL; and, once the latter reaches a critical threshold concentration, the AHL signal molecule binds the cognate LuxR-family sensor/regulator, which activates or represses target gene expression (Fuqua and Greenberg 2002).

In plant-pathogenic bacteria, expression of virulence factors is often dependent on AHL QS; as, for example, conjugation in Agrobacterium tumefaciens, cell-wall-degrading enzyme pro- 
duction in Erwinia carotovora, extracellular polysaccharide production in Pantoea stewartii subsp. stewartii, and traits involved in survival, host invasion, and virulence in Pseudomonas syringae pv. syringae (Barnard and Salmond 2007; Dulla and Lindow 2008; Quinones et al. 2004, 2005; von Bodman and Farrand 1995; von Bodman et al. 2003; Whitehead et al. 2001; Zhang et al. 1993). Generally, phytotoxin production is not regulated by QS (Bender et al. 1999). Nevertheless, recently, it has been demonstrated that the biosynthesis and export of toxoflavin by the rice pathogen Burkholderia glumae requires the regulator ToxJ, the expression of which is regulated by the TofI/R QS system (Kim et al. 2004).

Our previous studies demonstrated that $P$. corrugata $\mathrm{CFBP}$ 5454 produces $N$-hexanoyl-L-homoserine lactone (C6-HSL), 3-oxo-C6-HSL, and C8-HSL and this ability is well conserved within the species because strains with different origins and phenotypic and genetic characters produced the same AHL at comparable levels (Licciardello et al. 2007). The AHL QS system of $P$. corrugata was designated $\mathrm{Pcol} / \mathrm{PcoR}$, consisting of an AHL synthase, PcoI, and a transcriptional sensor/regulator belonging to the LuxR family protein, PcoR (Licciardello et al. 2007). The contribution of QS to TPN and antimicrobial activity was previously demonstrated (Licciardello et al. 2007). Interestingly, only the $P$. corrugata pcoR mutant and not the pcoI mutant induced significantly attenuated disease symptoms in tomato, suggesting an intricate network of regulation. To our knowledge, the identification and analysis of $P$. corrugata QS is the only available molecular study on this bacterial pathogen. The importance and conservation of QS in $P$. corrugata as well as the absence of further genetic and molecular information prompted us to investigate the DNA sequence adjacent to the QS locus because, often, QS-regulated genes are genetically linked. Downstream of pcoI, we identified a gene that encodes a transcriptional regulator of the LuxR family, which we designated $r f i A$. Importantly, $r f i A$ is cotranscribed with pcoI. Further sequencing of the downstream region revealed a 5,611-bp operon encoding for a tripartite resistance nodulation-cell-division (RND) transporter system. The role of RfiA, $\mathrm{QS}$, and the transporter system in LDP regulation and tomato virulence was investigated.

\section{RESULTS}

\section{Sequencing and analysis of genes adjacent to the QS pcoI/pcoR locus.}

Our previous studies determined that $P$. corrugata possesses an AHL QS system designated PcoI/R which plays a role in $P$. corrugata virulence (Licciardello et al. 2007). To further characterize the DNA region linked to the QS $p c o I / R$ locus within a previously sequenced $2.7-\mathrm{kb}$ region, we sequenced an additional 6.7-kb DNA region adjacent to and downstream of the pcoI gene (Fig. 1).

DNA sequence analysis of the newly sequenced region revealed four potential open reading frames (ORF) downstream of the $p c o I / R$ locus. The first ORF was closely associated with the pcoI locus, separated by only $32 \mathrm{bp}$ of DNA. This ORF shared $91 \%$ identity with the rfiA gene sequence of $P$. corrugata $2140 \mathrm{R}$, which is predicted to encode a transcriptional activator involved in the biosynthesis of antimicrobial compounds (this gene has only been annotated as a possible regulator of fungal inhibition without experimental evidence; GenBank accession number AF199370).

In addition, three ORF, designated $p c o A, p c o B$, and $p c o C$, were identified downstream of $r f i A$, transcribed in the opposite direction. The stop codon (TGA) of $p c o A$ overlapped the start coding region of $p c o B$ by $58 \mathrm{bp}$ and, similarly, the stop codon (TGA) of $p c o B$ overlapped the start coding region of $p c o C$ by
$4 \mathrm{bp}$, which indicates that $p c o A, p c o B$, and $p c o C$ are most probably organized as an operon. The $p c o A,-B$, and $-C$ genes are $1,428,1,161$, and 3,084 bp in size, respectively, and composition analysis revealed that the $\mathrm{G}+\mathrm{C}$ contents range from 62 to $66 \%$. Nucleotide sequence analysis revealed that these three genes encode proteins, which constitute a multidrug efflux system (discussed below).

\section{The rfiA gene encodes a regulator belonging to the LuxR family.}

Nucleotide sequence analysis revealed that $r f i A$ encoded a predicted 288-amino-acid protein. RfiA displayed $94 \%$ sequence identity (96\% homology) with a putative transcriptional activator of $P$. corrugata 2140R (AAG28559) and 51\% identity (65\% homology) with the protein SalA of $P$. syringae MIS38 (BAF76155). RfiA also showed 45\% identity (62\% homology) with the well-characterized SalA protein of $P$. syringae B301D (Lu et al. 2002; Wang et al. 2006). RfiA contains a DNA-binding domain with a helix-turn-helix motif characteristic of the LuxR family near its carboxy-terminus (amino acids 215 to 265). It consists of four helix bundles in which the central helices form the HTH motif (Fuqua and Greenberg 2002).

Unlike PcoR, RfiA does not contain the five highly conserved amino acids (Trp59, Tyr69, Asp79, Pro80, and Gly121) in the $N$-terminus characteristic of the autoinducer-binding subfamily of the QS LuxR-family proteins (Fuqua et al. 1996). Moreover, RfiA lacks the characteristic "acid pocket" composed of four highly invariant residues (Asp11, Asp12, Asp55, and Lys105) of members of the response regulator subfamily domains (Parkinson and Kofoid 1992).

\section{The rfiA gene is part}

\section{of the same transcriptional unit as pcoI.}

The first putative triplet codon for the rfiA ORF was located only $32 \mathrm{bp}$ downstream of the stop codon of the pcoI AHL synthase gene; therefore, it was of interest to determine whether the rfiA was part of the same transcriptional unit of pcoI. We used reverse transcription with three sets of oligonucleotides (Table 1) to determine whether the pcoI and rfiA genes are cotranscribed. Specifically, primer set PCR1 was used to amplify a segment of the pcoI gene, PCR2 to capture an intervening region between pcoI and $r f i A$, and PCR3 to amplify a region of the $r f i A$ gene. As expected, the PCR1 primer set yielded the expected 101-bp amplification product in the wild-type (WT) strain but not in the pcoI transposon insertional mutant GL1 (data not shown). Primer set PCR2 yielded a 614-bp amplicon in the WT strain, indicating that pcoI and $r f i A$ are cotranscribed. The $r f i A$ PCR3-specific amplicon was absent in the GL1 pcoI mutant strain, indicating that the transposon inserted in the pcoI gene had a polar effect on the cotranscribed $r f i A$ gene. Therefore, it was concluded that GL1 is a double $p c o I / r f i A$ mutant.

\section{PcoR and AHL activate pcoI and rfiA expression.}

In order to determine whether PcoR regulates pcoI expression, the promoter region of pcoI was cloned in the broadhost-range low-copy-number $\beta$-galactosidase promoter probe vector pMP220, yielding pMPPcoI. Promoter activity was determined in response to the growth phase of the WT strain CFBP 5454 and QS mutant derivatives. PcoI promoter activity was undetectable in the pcoR or pcoI P. corrugata mutants, indicating that it was under positive autoregulation, as is often the case with the $l u x I / R$ systems (Fig. 2A). The presence of a lux-box consensus sequence in the upstream region of pcoI further supported the idea that PcoR regulated pcoI expression. Exogenous addition of C6-HSL, C8-HSL, and 3-oxo-C6-HSL $(1 \mu \mathrm{M})$, the three signal molecules produced by $P$. corrugata 
CFBP 5454 (Licciardello et al. 2007), to the pcoI GL1 mutant harboring pMPPcoI restored promoter activity (Fig. 2B). Therefore, it seems that all three AHL are able to interact and activate PcoR; however, C8-HSL had the highest inducing activity $(P<0.05)$. Because $p c o I$ and rfiA are part of the same transcriptional unit, it was concluded that $r f i A$ was also under the control of pcoI promoter region.

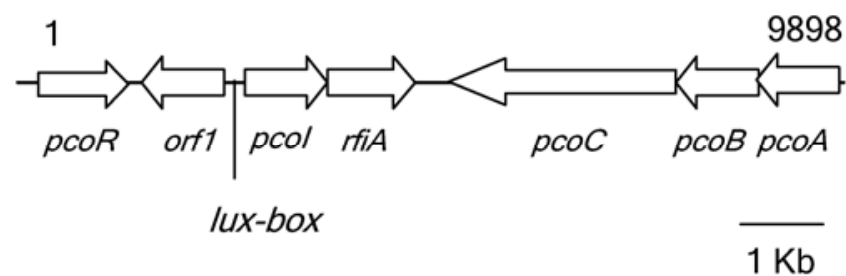

Fig. 1. Gene map of a 9.8-kb DNA region of Pseudomonas corrugata CFBP 5454. The rfiA gene and pcoABC operon are localized downstream of the $\mathrm{pcol} / \mathrm{R}$ quorum-sensing system. $r f i A$, oriented in the same direction as pcoI, encodes for an LuxR transcriptional activator protein. Genes $p c o A, p c o B$, and $p c o C$ form the $p c o A B C$ operon, which is divergently oriented, and encode for a resistance nodulation-cell-division transporter system.
The pcoABC operon encodes an RND transporter system and is regulated by $\mathrm{RfiA}$.

The pcoABC operon encodes three components of a tripartite RND transporter system. This is composed of an outer membrane protein (PcoA), a periplasmic membrane fusion protein $(\mathrm{PcoB})$, and a cytoplasmic RND transporter (PcoC) (Saier and Paulsen 2001). The PcoABC efflux system is highly homologous to the PseABC RND efflux system described in $P$. syringae pv. syringae $\mathrm{B} 301 \mathrm{D}$. In $P$. syringae, this system is localized in the syr-syp genomic island, which is involved in the secretion of lipopeptide toxins such as syringomicin and syringopeptins (Kang and Gross 2005). The PcoA-predicted protein (475 amino acids long) showed $67 \%$ identity and $82 \%$ similarity with PseA (ABN45752) and contains the TolC conserved domain. The putative PcoB protein, composed of 386 amino acids, showed $66 \%$ identity ( $80 \%$ similarity) with PseB (ABN45753) and contains the AcrA conserved domain, anchored to the inner membrane. The 1,027-amino-acid PcoC protein showed the highest homology (77\% identity, $87 \%$ similarity) with PseC (ABN45754) and contains the domain AcrB, composed of 12 transmembrane $\alpha$-helices and two large hydrophilic loops. The activity of a pcoA::lacZ promoter probe reporter construct expressed in GL1 (pcoI/rfiA mutant), GL2

Table 1. Bacterial strains, plasmids, and oligonucleotides used in this study

\begin{tabular}{|c|c|c|}
\hline Strains, plasmids, or oligonucleotides & Characteristics or sequences $^{a}$ & References or sources $^{b}$ \\
\hline \multicolumn{3}{|l|}{ Pseudomonas corrugata } \\
\hline CFBP 5454 & Wild type, source of $p c o I$ and $p c o R$ & CFBP \\
\hline GL1 & pcoI362::Tn5, $\mathrm{Km}^{\mathrm{r}}$ & Licciardello et al. 2007 \\
\hline GL2 & pcoR76::Tn5, $\mathrm{Km}^{\mathrm{r}}$ & Licciardello et al. 2007 \\
\hline GLRFIA & $r f i A::$ pKnock, $\mathrm{Km}^{\mathrm{r}}$ & This study \\
\hline GLPCOA & pcoA:: pKnock, $\mathrm{Km}^{\mathrm{r}}$ & This study \\
\hline \multicolumn{3}{|l|}{ Escherichia coli } \\
\hline pLc3.34 & pLAFR3 containing P. corrugata CFBP 5454 DNA, $\mathrm{Tc}^{\mathrm{r}}$ & DISTEF \\
\hline $\mathrm{DH} 5 \alpha$ & $\begin{array}{l}\mathrm{F} 2 \text { f80dlacZDM15 D(lacZYA-argF }) \text { U169 endA1 recA1 hsdR17 deoR gyrA96 thi-1 } \\
\text { relA1 supE44 }\end{array}$ & Sambrook et al. 1989 \\
\hline CC118גpir & $\begin{array}{l}\Delta(\text { ara, leu }) 7697 \text { araD139 } \Delta l a c X 74 \text { gale galK phoA20 thi-1 rpsE rpoB }\left(\mathrm{Rf}^{\mathrm{T}}\right) \\
\operatorname{argE}(\mathrm{Am}) \text { recA1 } \lambda \text { pir }\end{array}$ & Herrero et al. 1990 \\
\hline \multicolumn{3}{|c|}{ 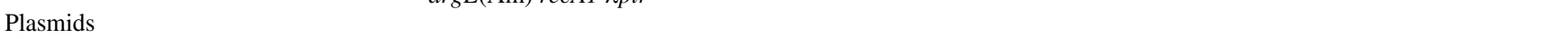 } \\
\hline pCR2.1 & Cloning vector TA, $\mathrm{Amp}^{\mathrm{r}}$ & Invitrogen \\
\hline pRK2013 & $\mathrm{Km}^{\mathrm{r}} \mathrm{Tra}^{+} \mathrm{Mob}^{+} \mathrm{ColE} 1$ replicon & Figurski and Helinski 1979 \\
\hline pMOSBlue & Cloning vector, $\mathrm{Amp}^{\mathrm{r}}$ & Amersham-Pharmacia \\
\hline pMP220 & Promoter probe vector, $\mathrm{IncP} \mathrm{Tc}^{\mathrm{r}}$ & Spaink et al. 1987 \\
\hline pBBR1MCS-5 & Broad-host-range vector, $\mathrm{Gm}^{\mathrm{r}}$ & Kovach et al. 1975 \\
\hline pKNOCK-Km ${ }^{r}$ & Mobilizable suicide vector, $\mathrm{Km}^{\mathrm{r}}$ & Alexeyev, 1999 \\
\hline pGEM-T & Cloning vector; $\mathrm{Amp}^{\mathrm{r}}$ & Promega \\
\hline pMOPcoI & pcol promoter cloned in pMOSblue; $\mathrm{Amp}^{\mathrm{r}}$ & This study \\
\hline pGEPcoA & pcoA promoter cloned in $\mathrm{pGem}-\mathrm{T} ; \mathrm{Amp}^{\mathrm{r}}$ & This study \\
\hline pMPPcoI & pcoI promoter cloned in pMP220 & This study \\
\hline pMPPcoA & pcoA promoter cloned in $\mathrm{pMP} 220$ & This study \\
\hline pKMRfiA & pKNOCK containing an internal fragment of $P$. corrugata CFBP 5454 rfiA gene & This study \\
\hline pKMPcoA & pKNOCK containing an internal fragment of $P$. corrugata CFBP 5454 pcoA gene & This study \\
\hline pBBR-RfiA & pBBR1MCS-5 containing the full length $P$. corrugata CFBP 5454 rfiA gene & This study \\
\hline \multicolumn{3}{|l|}{ Oligonucleotides } \\
\hline PrpcoI-fw & 5'-CGGTACCCACTGTCATCAGTGAAAGC-3' & This study \\
\hline PrpcoI-rew & 5'-GTCTAGAGGGATTTTCGAGTAAGATG-3' & This study \\
\hline PrpcoA-fw & 5'-GCTCTAGATTGAAGACATGCATAGG-3' & This study \\
\hline PrpcoA-rew & 5'-GGGTACCTATCGCGAGCAGGCTCG-3' & This study \\
\hline RfiAKn-fw & 5'-CTCTAGAACGACCTGATACTTACCG-3' & This study \\
\hline RfiAKn-rew & 5'-GGGTACCTTATGGCAGCACGCTTCAG-3' & This study \\
\hline PcoAKn-fw & 5'-CAGGATCCTGGGAGATCGACCTGTTCG-3' & This study \\
\hline PcoAKn-rew & 5'-GAAAGCTTTCGAACGACTCACGAAAGCC-3' & This study \\
\hline RFIA-fw & 5'-AGAAGCTTCTATAACACCAAGACTCTG-3' & This study \\
\hline RFIA-rew & 5'-TTGGATCCAACGTTCTATACGGCTTGG-3' & This study \\
\hline PCR1-Fw & 5'-CATCAGGCCTCACTCACACACT-3' & This study \\
\hline PCR1-Rew & $5^{\prime}$-GTTGGCCTGGGTGACTTCTC-3' & This study \\
\hline PCR2-Fw & 5'-CATCAGGCCTCACTCACACACT-3' & This study \\
\hline PCR2-Rew & 5'-ATGCGTTGCATCGACAGGTAT-3' & This study \\
\hline PCR3-Fw & 5'-CTCTAGAACGACCTCATACTTACCG-3' & This study \\
\hline PCR3-Rew & 5'-GGGTACCTTATGGCAGCACGCTTCAG-3' & This study \\
\hline
\end{tabular}

${ }^{\mathrm{a}} \mathrm{Km}^{\mathrm{r}}, \mathrm{Rf}^{\mathrm{r}}, \mathrm{Tc}^{\mathrm{r}}, \mathrm{Amp}^{\mathrm{r}}$, and $\mathrm{Gm}^{\mathrm{r}}$ indicate resistance to kanamycin, rifampicin, tetracycline, ampicillin, and gentamicin, respectively.

${ }^{\mathrm{b}} \mathrm{CFBP}=$ Collection Francaise de Bacteries Phytopathogenes, Angers, France; DISTEF = Dipartimento di Scienze e Tecnologie Fitosanitarie, Catania, Italy 
(pcoR mutant), and GLRFIA (rfiA mutant) was 10-fold lower compared with the activity measured in the parent strain, indicating that $p c o A$ is positively regulated by QS or RfiA. We then introduced a plasmid constitutively expressing $r f i A$ (i.e., pBBRRfiA, where rfiA is expressed from the lac promoter) in both GL1 and GL2 $P$. corrugata mutants harboring the pcoA::lacZ transcriptional fusion. The expression of $r f i A$ in
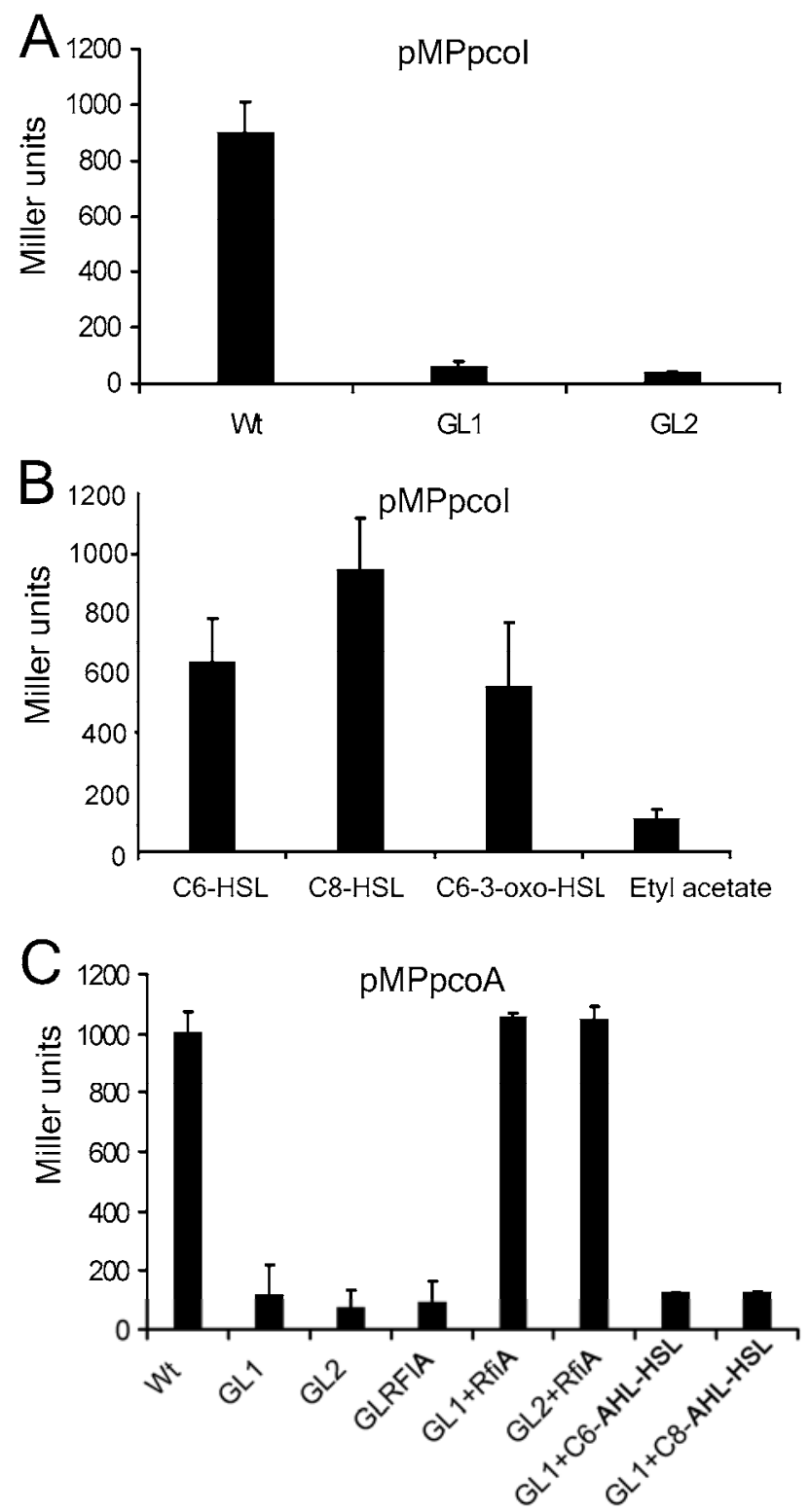

Fig. 2. pcoI and pcoA promoter activities in the parent strain Pseudomonas corrugata CFBP 5454 and mutant derivatives. Values are averages of at least three independent experiments; the standard deviation of the mean are indicated by the bars. A, pcoI promoter activities in the parent strain and quorum-sensing (QS) mutant derivatives obtained by using the pcoIlac $Z$ reporter construct. pcoI gene expression was under positive feedback QS regulation. B, Effect of exogenous $N$-hexanoyl-L-homoserine lactone (C6-HSL), C8-HSL, and C6-3-oxo-HSL on pcoI transcription as measured using GL1 (pMPPcoI). The three lactones, and particularly C8-HSL, are effective in restoring pcoI promoter activity in the GL1 mutant ( $p c o I-)$ in presence of the $p c o I-l a c Z$ reporter construct. $\mathbf{C}, p c o A B C$ operon promoter activities in the parent strain $P$. corrugata 5454 and QS mutant derivatives by using the pcoA-lac $Z$ reporter construct. Expression of the $p c o A B C$ operon requires both the acyl-homoserine lactone (AHL)-QS system and the RfiA activator but promoter activities were fully restored in the QS mutant derivatives only by the presence of pBBRRfiA, which carried the intact $r f i A$ gene, and not by exogenous AHL. trans restored $p c o A$ promoter activity in both mutants to the parent strain levels, whereas exogenous addition of the three AHL produced by $P$. corrugata had no effect on the promoter activity (Fig. 2C). This data indicates a hierarchical regulatory scenario in which the PcoR-AHL complex regulates the $p c o I / r f i A$ operon and, in turn, RfiA activates $p c o A B C$. Therefore, it was concluded that the expression of the $p c o A B C$ transporter system is indirectly controlled by QS via RfiA.

\section{RfiA regulates LDP secretion.}

Our previous studies demonstrated that the antimicrobial activity of $P$. corrugata was altered in QS mutants (Licciardello et al. 2007). Because $P$. corrugata is known to produce the antimicrobial and phytotoxic LDP cormycin A and corpeptines A and B (Emanuele et al. 1998; Scaloni et al. 2004), we investigated whether LDP production is population-density dependent and whether it is regulated by the PcoI/R QS system or by RfiA.

We performed the production profile during bacterial growth of AHL and LDP in P. corrugata CFBP 5454 as described in the Materials and Methods section. AHL abundance was indirectly quantified by measuring the amount of violacein produced by the biosensor Chromobacterium violaceum CV026 (Fig. 3). LDP production, on the other hand, was assayed by inhibition of in vitro growth of Rhodotorula pilimanae (cormycin) and Bacillus megaterium (cormycin and corpeptines). AHL and LDP production were first detected in culture after $16 \mathrm{~h}$ of growth with cell concentration as low as $1.6 \times 10^{8}$ $\mathrm{CFU} \mathrm{ml} \mathrm{m}^{-1}$. Culture filtrates displayed inhibition zones of 4.5 and $2.5 \mathrm{~mm}$ against $R$. pilimanae and $B$. megaterium, respectively (Fig. 3). However, LDP and AHL concentration increased rapidly at higher bacterial densities; maximum LDP concentration was observed at cell densities over $6 \times 10^{9} \mathrm{CFU} \mathrm{ml}{ }^{-1}$ (late exponential growth phase) when inhibition zones against $R$. pilimanae and $B$. megaterium were 7 and $5 \mathrm{~mm}$, respectively (Fig. 3). Thus, it was concluded that LDP synthesis in $P$. corrugata CFBP 5454 occurs in a cell-density-dependent manner, with a trend similar to AHL production.

GL1 (pcoI/rfiA double mutant), GL2 (pcoR mutant), and GLRFIA (rfiA mutant) did not inhibit the growth of LDP-sensitive indicator microbes, suggesting they were unable to produce and/or secrete LDP (Fig. 4A). Expression in trans of the

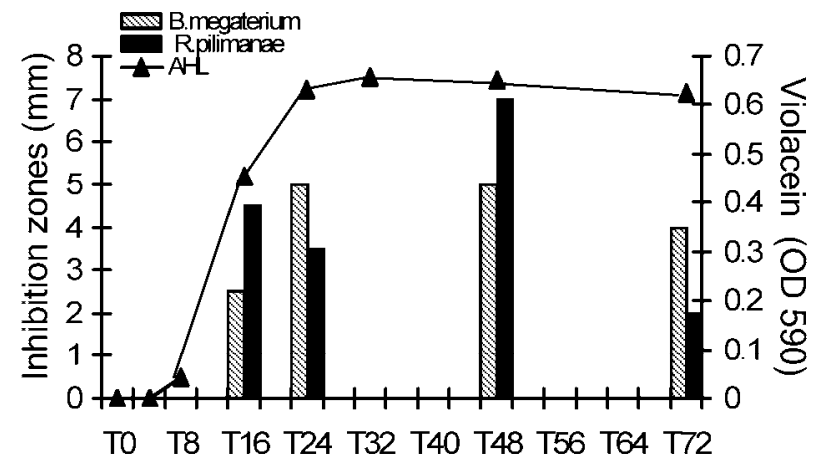

Time (h)

Fig. 3. Lipodepsipeptide and acyl-homoserine lactone (AHL) production in Pseudomonas corrugata CFBP 5454 during growth phase. Lipodepsipeptide production and secretion was evaluated by antimicrobial activity of the culture filtrates (10x) recovered at 8, 16, 24, 48, and $72 \mathrm{~h}$ after inoculation on inducing conditions against Rhodotorula pilimanae and Bacillus megaterium indicator microorganisms on potato dextrose agar medium. The values of the inhibition zones $(\mathrm{mm})$ are indicated by the bars. Values are the means of three replications. Results presented are representative of three different experiments. AHL biosynthesis was indirectly measured as violacein produced by a bioassay using the biosensor Chromobacterium violaceum CV026. Values are the means of 10 replications. 


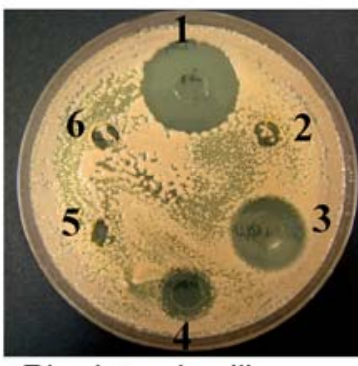

Rhodotorula pilimanae

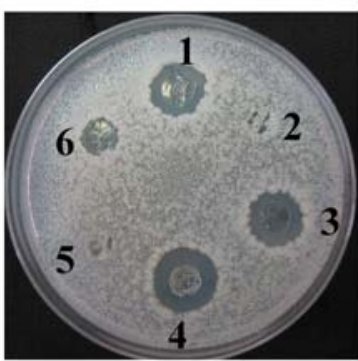

Bacillus megaterium
$\mathrm{B}_{6}$

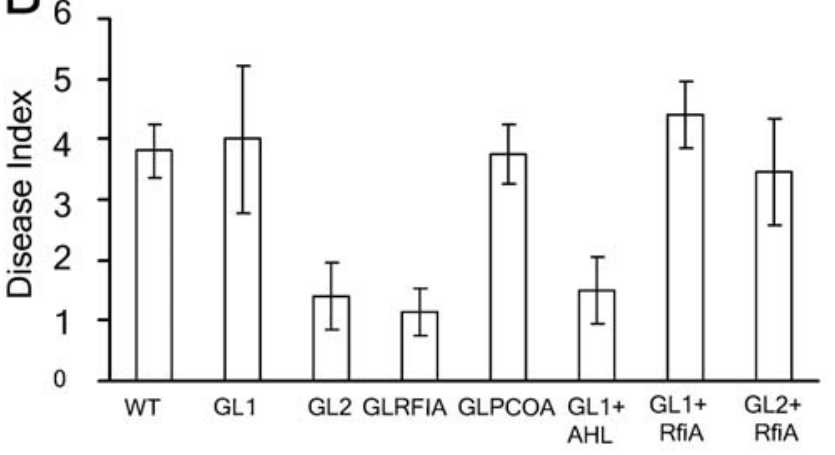

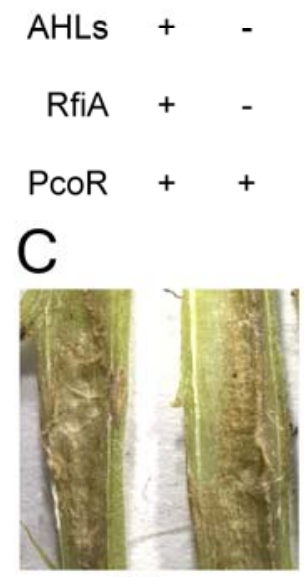

WT

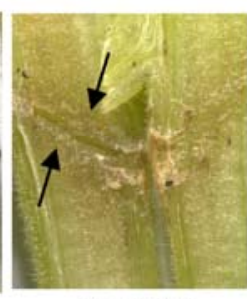

GLRFIA

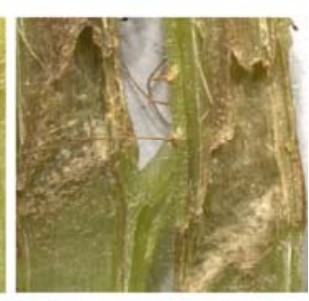

GLPCOA
Fig. 4. Biological activity of the parent strain Pseudomonas corrugata CFBP 5454 and mutant derivatives. A, Lipodepsipeptide (LDP) production. Culture filtrates $(10 \times)$ were tested on potato dextrose agar medium overlaid with Rhodotorula pilimanae and Bacillus megaterium indicator microorganisms: 1 = wild type (WT), $2=\mathrm{GL} 1$ (pcoI/rfiA double mutant), $3=$ GL1 (pcoI/rfiA double mutant) + pBBRRfiA, $4=$ GLPCOA ( $p c o A$ mutant), $5=$ GLRFIA ( $r f i A$ mutant), $6=$ GL2 (pcoR mutant). No LDP were detected in quorum-sensing and RfiA mutants. The complementation of the GL1 (pcoI/rfiA double mutant) with the intact $r f i A$ gene through the pBBRRfiA plasmid could restore LDP production. The inhibition zone produced by the GLPCOA ( $p c o A$ mutant) culture filtrate was slightly reduced compared with the WT. Results presented are representative of two different experiments with three replicates for each. B, Mean disease index (DI) of tomato plants inoculated with the parent strain $P$. corrugata CFBP 5454 (WT) and GL1 (pcoI/rfiA double mutant), GL2 (pcoR mutant), GLRFIA ( $r f i A$ mutant), and GLPCOA ( $p c o A$ mutant) mutant derivatives, GL1 with the addition of exogenous acyl-homoserine lactones (GL1+AHL), and GL1 and GL2 complemented in trans with intact rfiA (GL1+RfiA and GL2+RfiA, respectively). Error bars represent the standard deviation of the mean DI obtained from 20 individual disease rating scores. Below the graphic, the presence of AHL (either produced by the bacterial strain or provided exogenously) and the regulators PcoR and RfiA in the interaction with tomato plant are reported. $\mathbf{C}$, Stem pith symptoms in tomato plants prick inoculated with bacterial cells of the parent strain and GLRFIA ( $r f i A$ mutant) and GLPCOA ( $p c o A$ mutant). Plants inoculated with the GLRFIA mutants did not show necrosis or hollowing of the pith, whereas the trace of the wound caused by inoculation is still visible.
rfiA gene in the GL1 mutant by introducing pBBRRfiA restored the antimicrobial activity to the WT strain level, which suggested that RfiA was regulating LDP production (Fig. 4A). A mutation in the $p c o A$ transporter gene led only to the partial loss of antimicrobial activity because GLPCOA ( $p c o A$ mutant) culture filtrates $(P<0.05)$ (Fig. 4A) displayed inhibition zones against $R$. pilimanae and $B$. megaterium of approximately 48 and $46 \%$ respectively, compared with those of the parental strain CFBP 5454. This data indicated that the PcoABC efflux system had a role in LDP secretion but it was not essential because, most probably, $P$. corrugata possesses other efflux pumps able to transport LDP.

\section{The RfiA and PcoR regulators are involved in $P$. corrugata tomato virulence.}

The contributions of RfiA, PcoABC, and the PcoI/R QS system were examined in the formation of stem pith necrosis. The parent strain was compared with the mutants on the basis of its ability to induce symptoms in artificially inoculated tomato stem pith. Disease rating scores were considered and used to calculate a mean disease index (DI). The summary of these in planta infection studies is presented in Figure 4B and C. Plants inoculated with GL1 (pcoI/rfiA double mutant) and GLPCOA ( $p c o A$ mutant) displayed symptoms and DI similar to that of the parent strain (Fig. 4B). Stem-pith-infected tissues appeared as necrotic, partially dehydrated, and hollow (Fig. 4C). Most of the plants inoculated with GL2 ( $p c o R$ mutant) and GLRFIA (rfiA mutant) showed only a dark discoloration along the pin puncture and were scored 1 on the susceptibility scale (Fig. 4B). On the remaining plants, lesions were significantly reduced in length compared with those caused by the parent strain and were only discolored (Fig. 4C). The typical necrosis of the TPN syndrome was not observed (score 2). Expression of rfiA in trans in the GL2 mutant restored the virulence nearly to the same levels of that of the parent strain whereas, in GL1, virulence was maintained. Therefore, it was concluded that RfiA is of pivotal importance in virulence. In order to further assess the role of AHL, we inoculated GL1 with $5 \mu \mathrm{l}$ of C6-HSL and C8-HSL $\left(5 \mu \mathrm{g} \mathrm{ml}^{-1}\right)$ by pipetting into the inoculation wounds. GL1 exposed to exogenously added AHL showed symptoms similar to those induced by the GL2 and GLRFIA mutants (i.e., reduction of lesion extension and necrosis) (Fig. 4B). These results indicated that there were two conditions in which $P$. corrugata was virulent toward tomato: presence of PcoR in the absence of AHL or with RfiA. Therefore, it was concluded that, in the presence of AHL, PcoR activates gene expression of virulence factors via RfiA. In the absence of AHL signals, PcoR, however, can induce virulence gene expression via another yet unknown mechanism (Fig. 5). Finally, it was observed that the $p c o A B C$ transport system was not pivotal for virulence because a $p c o A$ mutant retained its ability to be pathogenic (Fig. 4B and C). Most probably, therefore, other LDP transport efflux systems are operational in P. corrugata.

\section{DISCUSSION}

In this study, we have further demonstrated that, in P. corrugata, virulence is regulated by QS. Injection of high-density inoculum within the stem of a wide range of plant species, including members of Solanaceae (egg plant and bell pepper) and species in other families (cucumber, zucchini, bean, and cauliflower) led to pith necrosis (Siverio et al. 1993; Sutra et al. 1997; Catara et al. 1997, 2002). In nature, however, the disease is only widespread in tomato, with just a few cases of infections being reported on pepper and one report on chrysanthemum and geranium (Catara 2007). Therefore, it is tempting to speculate that, in some plants, $P$. corrugata is not able to reach the bacte- 
rial density necessary for a synchronous concerted attack through activation of effectors or virulence factors.

$P$. corrugata has a conserved AHL QS system designated $\mathrm{PcoI} / \mathrm{R}$ which plays a significant role in tomato virulence (Licciardello et al. 2007). In this study, we sequenced the DNA region downstream of the AHL QS locus, and this led to the identification of genes of considerable phytopathological interest. A regulatory gene, $r f i A$, located at the right border of the pcoI gene, was identified as a member of the LuxR family of regulatory proteins. RfiA contains an HTH DNA motif in the Cterminus characteristic of the LuxR family of bacterial regulatory proteins but lacks the conserved residues at the $N$-terminus characteristic of the two major LuxR subfamilies (Finney et al. 2002). Due to high sequence similarity and domain homologies, RfiA could belong to the novel LuxR subfamily described for the SalA and SyrF regulators in P. syringae pv. syringae B301D (Lu et al. 2002). SalA and SyrF are localized in the syr-syp genomic island and regulate syringomycin and syringopeptins production (Wang et al. 2006). However, in P. syringae pv. syringae, the production of LDP is not regulated by QS but is directly controlled by a complex regulatory cascade which involves the two-component sensor/regulator GacS/GacA and the transcriptional activators SalA and SyrF (Wang et al. 2006). Interestingly, we found that, in $P$. corrugata, the newly characterized $r f i A$ forms an operon with the pcoI AHL-synthase gene. To our knowledge, this is the first report of a luxI homolog cotranscribed with a regulatory gene. We demonstrated that PcoR activates pcoI expression in the presence of exogenous AHL via a typical positive-feedback regulatory loop. Because $p c o I$ and $r f i A$ constitute an operon, the expression of $r f i A$ is directly regulated by the PcoR-AHL complex.

Further sequencing revealed the presence of an RND-type efflux system next to $r f i A$, designated $p c o A B C$. The RND superfamily of multidrug transporters is composed of eight phylogenetic families involved in the export of several compounds, including heavy metals, multiple drugs, and lipo-oligosaccharides (Murakami and Yamaguchi 2003). The predicted PcoABC system was highly homologous to the PseABC efflux system of $P$. syringae pv. syringae $\mathrm{B} 301 \mathrm{D}$, where it has a role in the secretion of syringomycin and syringopeptins (Kang and Gross 2005). We have shown that the $p c o A B C$ operon is under positive regulation by RfiA and, indirectly, by the PcoI/R system. Therefore, the regulation of the $P$. corrugata pcoABC operon occurs according to a hierarchical model. In late exponential growth, the bacterium activates AHL production, which results in the formation of the AHL-PcoR complex that most probably binds the lux-box element in the pcoI promoter and activates AHL-synthase expression as well as $r f i A$ transcription. RfiA, in turn, activates the transcription of the $p c o A B C$ operon either directly or indirectly. Further experiments are needed to molecularly confirm this working model.

P. corrugata produces the LDP corpeptin A and corpeptin B, two isoforms consisting of 22-amino-acid residues, which are toxic when inoculated into tobacco leaves and are also antimicrobial against B. megaterium (Emanuele et al. 1998). Moreover, some of the strains also produce cormycin A, a lipodepsinonapeptide which shows in vitro inhibition of not only $B$. megaterium but also $R$. pilimanae, and exhibited phytotoxic activity (Scaloni et al. 2004). Mutants unable to produce toxins did not inhibit growth of the two target microorganisms and did not induce necrotic lesions in tomato leaves or stems (Chun and Leary 1989). Phenotype analysis of the $p c o I / r f i A, p c o R$, and $r f i A$ mutants revealed that they were impaired in LDP secretion because their culture filtrates were unable to inhibit the growth of the $R$. pilimanae and B. megaterium target organisms. Moreover, time-course monitoring of antimicrobial activity of $P$. corrugata CFBP 5454 showed that LDP are not produced until high popu- lation densities are reached. The importance of RfiA in the development of the disease symptoms in tomato plants was demonstrated by the reduction of lesions and the absence of necrosis within the stem pith tissues inoculated with the rfiA mutant compared with those inoculated with the WT strain CFBP 5454. Similarly, a $P$. syringae pv. syringae salA mutant failed to produce syringomycin and was significantly less virulent than the WT strain B301D (Lu et al. 2002). SalA is essential for the expression of $s y r B 1$, a biosynthesis gene for syringomycin ( $\mathrm{Lu}$ et al. 2002). The PcoABC and PseABC RND transport systems of $P$. corrugata and $P$. syringae pv. syringae, respectively, share considerable homology. Both systems were shown to be involved in LDP secretion; however, both $p c o A B C$ and pseABC mutants were as virulent as their WT strains (Kang and Gross 2005; this study). In $P$. syringae pv. syringae, two additional $\mathrm{ABC}$ transporters, encoded by $s y r D$ and $s y p D$, are also involved in the secretion of syringomycin and syringopeptins (Quigley et al. 1993). When the pcoA mutant was grown in laboratory culture media, it produced and secreted LDP, indicating that other LDP secretion mechanisms also exist in $P$. corrugata.

Even in Burkholderia glumae, phytotoxin production and transport is regulated indirectly by AHL QS via the ToxJ regulator. ToxJ is a transcriptional regulator similar to RfiA, which is regulated by the TofI/R AHL QS system and, in turn, regulates toxoflavin production in a cell-density-dependent manner (Kim et al. 2004). ToxJ simultaneously activates the expression of the toxABCDE operon responsible for toxoflavin biosynthesis and the toxFGHI operon responsible for its transport (Kim et al. 2004). RfiA, SalA, SyrF, and ToxJ belong to a new emerging subfamily of LuxR-family regulators which, thus far, have been shown to be involved in virulence and the regulation of the RND-type transporters in toxin secretion in phytopathogenic bacteria. It is likely that these regulators are also involved in regulating other virulence loci, including LDP structural genes as well as other LDP secretion systems.

Plant pathogenicity studies revealed that PcoR and RfiA play a role in bacterial virulence in tomato (Fig. 4B). As shown by Licciardello and associates (2007), the GL1 mutant (which is a double pcoI/rfiA mutant) was as virulent in planta as the WT, suggesting that the sole presence of PcoR in the cell is sufficient for $P$. corrugata to be pathogenic. However, when PcoR is in the cell with AHL and no RfiA, $P$. corrugata is less virulent, as in the case of the addition of exogenous AHL to the pcoI/rfiA mutant. The presence of RfiA is crucial for bacterial virulence. Like other LuxR-type regulators, RfiA does not require AHL to

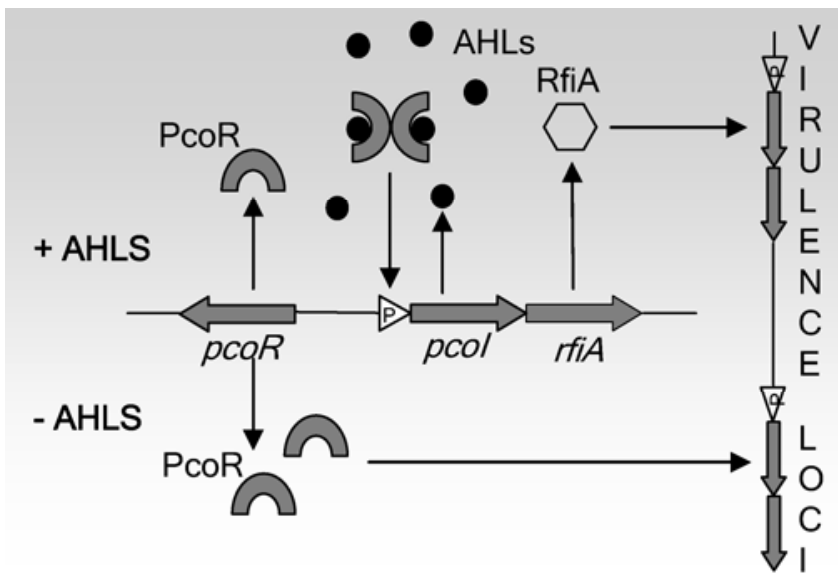

Fig. 5. Working model for acyl-homoserine lactone (AHL) quorum-sensing (QS) and RfiA involvement in Pseudomonas corrugata virulence. In the presence of AHL QS, virulence is regulated via RfiA. In absence of AHL, PcoR does not activate transcription of the pcoI/rfiA locus and virulence is regulated by PcoR. 
be active; therefore, its complementation in trans is sufficient to restore pathogenicity in the $p c o R$ mutant in absence of AHL. A working model of how the PcoI/PcoR/RfiA system could be involved in virulence, in which either QS regulates the production of RfiA or PcoR regulates virulence independently of AHL, is shown in Figure 5. Therefore, it is hypothesized that PcoR acts directly or indirectly in the absence of AHL as an activator or repressor of different virulence-associated genes. There are several reports of QS-LuxR family proteins which are active independently of AHL, as is the case for CarR of Serratia spp. (Cox et al. 1998), SmaR of Erwinia spp. (Slater et al. 2003), and EsaR of Pantoea stewartii (von Bodman et al. 1998). Further molecular studies of this working model may shed light on the mechanisms by which PcoR and RfiA contribute to virulence gene expression.

\section{MATERIALS AND METHODS}

\section{Bacterial strains, plasmids, and media.}

Pseudomonas corrugata strains, plasmids, and primers used in this study are listed in Table 1 . P. corrugata strains were routinely grown at $28^{\circ} \mathrm{C}$ in either nutrient agar (Oxoid, Milan, Italy) plus $1 \%$ dextrose (NDA) or in Luria-Bertani (LB) agar. Transcriptional fusion plasmids for the various gene promoters based on the pMP220 promoter probe vector were constructed as follows. The 695-bp fragment containing the pcoI promoter region was amplified by polymerase chain reaction (PCR) by using Vent DNA polymerase (New England Biolabs, Frankfurt, Germany) according to the instructions of the supplier, genomic DNA of $P$. corrugata CFBP 5454 as the template, and oligonucleotides PrpcoI-fw and PrpcoI-rew (Table 1). The fragment was then cloned in pMOSBlue (Amersham Biosciences, Amersham, U.K.), yielding pMOPcoI, and verified by DNA sequencing. The pcoI promoter was then removed as a KpnI-XbaI fragment and cloned in the corresponding sites in pMP220, yielding pMPPcoI. Similarly, the $p c o A$ promoter was amplified as a 220 bp fragment by using oligonucleotides PrpcoA-fw and PrpcoArew (Table 1) and cloned in pGEM-T, yielding pGEPcoA. The $p c o A$ promoter was then removed as a KpnI-XbaI fragment and cloned in pMP220, yielding pMPPcoA. The full-length $r f i A$ gene (912 bp) was amplified by PCR by using Taq DNA Polymerase Recombinant (Invitrogen, Milan, Italy) and primers RFIA-fw and RFIA-rew and cloned in pCR2.1 vector (Invitrogen). The fragment was then removed as a BamHI-HindIII and cloned in the corresponding sites in pBBR1MCS-5 (Kovach et al. 1995) according to the instructions of the supplier, yielding pBBR-RfiA. Antibiotics were added as required at the following final concentrations: ampicillin, $100 \mu \mathrm{g} \mathrm{ml}^{-1}$; tetracycline, $15 \mu \mathrm{g}$ $\mathrm{ml}^{-1}$ (Escherichia coli) or $40 \mu \mathrm{g} \mathrm{ml}^{-1}$ (Pseudomonas spp.); gentamicin, $10 \mu \mathrm{g} \mathrm{ml}^{-1}$ (E. coli) or $30 \mu \mathrm{g} \mathrm{ml}^{-1}$ (Pseudomonas spp.); and kanamycin, $50 \mu \mathrm{g} \mathrm{ml}^{-1}$ (E. coli and C. violaceum) or $100 \mu \mathrm{g}$ $\mathrm{ml}^{-1}$ (Pseudomonas spp.).

\section{Recombinant DNA techniques.}

DNA manipulations, including digestion with restriction enzymes, agarose gel electrophoresis, purification of DNA fragments, ligation with T4 ligase, DNA hybridization, radioactive labeling by random priming, and transformation of $E$. coli, were performed as described by Sambrook and associates (1989). Southern hybridizations were performed by using $\mathrm{N}+\mathrm{Hybond}$ membranes (Amersham Biosciences); plasmids were purified using Jet star columns (Genomed $\mathrm{GmbH}$, Löhne, Germany) or by the alkaline lysis method (Birnboim 1983); total DNA from Pseudomonas spp. was isolated by Sarkosyl-pronase lysis as described previously (Better et al. 1983) or by a Puregene DNA isolation kit (Gentra Systems, Minneapolis, MN, U.S.A.), according to the manufacturer's instructions. Triparental matings from $E$. coli to $P$. corrugata were carried out with the helper strain E. coli (pRK2013) (Figurski and Helinski 1979).

\section{DNA sequencing and sequence analysis.}

The cosmid pLC3.34 DNA insert was partially sequenced on both strands (Macrogen, Inc, Seoul, Korea). Sequencing for verification of cloned DNA inserts was determined by BMRCRIBI (University of Padua, Italy). Homology searches of nucleotide and protein sequences were performed using the BLAST searching program (Altschul et al. 1990).

\section{Cloning and construction of the genomic rfiA and pcoA null mutants of $P$. corrugata CFBP 5454.}

The $P$. corrugata CFBP 5454 rfiA and pcoA genes were amplified, in part, by PCR in order to generate independent genomic mutations in $P$. corrugata CFBP 5454. The central part of the $r f i A$ gene was amplified by PCR as a 678-bp fragment using primers RfiAKn-fw and RfiAKn-rew (Table 1) and cloned as a $K p n \mathrm{I}-\mathrm{Xba \textrm {I }}$ fragment in the corresponding sites in $\mathrm{pKNOCK}$ $\mathrm{Km}$, generating pKMRfiA. The central part of the $p c o A$ gene was amplified by PCR as an 818-bp fragment using primers PcoAKn-fw and PcoAKn-rew (Table 1) cloned as a BamHIHindIII fragment in the corresponding sites in pKNOCK-Km (Alexeyev 1999), generating pKMPcoA. The pKMRfiA and pKMPcoA plasmids were then used as a suicide delivery system in order to create $r f i A$ and $p c o A$ knockout mutants through homologous recombination in strain CFBP 5454, as described previously (Alexeyev 1999), generating GLRFIA and GLPCOA, respectively. The fidelity of the marker exchange events was confirmed by Southern analysis (data not shown).

\section{Reporter gene fusion assay.}

$\beta$-Galactosidase activities were determined during growth in LB medium essentially as described by Miller (1972), with the modifications of Stachel and associates (1985). All experiments were performed in triplicate. $\beta$-Galactosidase activities were determined after a $20-\mathrm{ml}$ LB medium culture started with an initial inoculum of $1.6 \times 10^{8} \mathrm{CFU}$.

\section{Reverse-transcriptase PCR analysis.}

$P$. corrugata CFBP 5454 and GL1 and GLRFIA mutant derivatives were grown in LB medium to the exponential growth phase (14 h after inoculation); total RNA was isolated using a commercial RNA extraction kit (Purescript, Gentra) as recommended by manufacturer. For this purpose, triplicate samples $(1 \mathrm{ml})$ were removed from $P$. corrugata cultures (optical density at $600 \mathrm{~nm}$ of 0.2 to 0.4 ) grown overnight. RNA samples were quantitatively analyzed by agarose gel electrophoresis. Following a DNAse purification step by DNAse I (Invitrogen), $200 \mathrm{ng}$ of total RNA was used in each $20-\mu$ l reaction containing one unit of Superscript III reverse transcriptase (Invitrogen), 10 pmol random examer (Invitrogen), and 10 pmol dNTPs. Samples in which reverse transcriptase was not added were used as negative controls. The reverse transcription reaction was performed at $50^{\circ} \mathrm{C}$ for $1 \mathrm{~h}$ followed by $15 \mathrm{~min}$ at $65^{\circ} \mathrm{C}$, according to the manufacturer's instructions. PCR reactions were performed using a Gene Amp PCR system 9700 (PE Applied Biosystem, Milan, Italy) under the following conditions: an initial $94^{\circ} \mathrm{C}$ for $3 \mathrm{~min}$; followed by 35 cycles of $94^{\circ} \mathrm{C}$ for $30 \mathrm{~s}$, $58^{\circ} \mathrm{C}$ for $30 \mathrm{~s}$, and $72^{\circ} \mathrm{C}$ for $1 \mathrm{~min}$; and a final extension of $72^{\circ} \mathrm{C}$ for $10 \mathrm{~min}$. Three sets of primers were used to amplify a partial pcoI gene region (PCR1) (101 bp), a pcoI-rfiA overlapping region (PCR2) (614 bp), and a partial $r f i A$ gene region (PCR3) (678 bp) (Table 1). P. corrugata CFBP 5454 DNA was used as a positive control. As a negative control, PCR reactions with the same primer sets were performed using RNA samples that had not been reverse transcribed. 
Culture filtrate preparation.

$P$. corrugata culture filtrates were used to assess AHL and LDP production. Culture filtrates were prepared according to Cirvilleri and associates (2005), with minor modifications. Bacterial strains were grown in IMM (Surico et al. 1988) at $28^{\circ} \mathrm{C}$ for 4 days. The time course production was determined by sampling aliquots of $20 \mathrm{ml}$ of culture incubated in a orbital shaker from triplicate flasks immediately after inoculation and after 4, 8, 16, 24, 32, 48, 72, and $96 \mathrm{~h}$. The mutant and WT strain activities were also assessed in 4-day-old still cultures. After centrifugation $(9000 \times g, 20 \mathrm{~min})$, the supernatant was passed through a $0.22-\mu \mathrm{m}$ Millipore filter (Millipore, Billerica, MA, U.S.A.) to obtain cell-free culture filtrates. Aliquots of samples at time (T) 8, 16, 24, 48, 72, and 96 were $10 \times$ concentrated by using the Vacufuge concentrator 5301(Eppendorf, Milan, Italy) for LDP bioassay.

\section{Bioassay for AHL production.}

AHL were quantified by adding the culture filtrates of $P$. corrugata CFBP 5454 or its mutant derivatives to CV026 liquid cultures and measuring violacein formation, which is dependent upon the external addition of medium-chain-length lactones (Martinelli et al. 2004). Experiments were conducted in microtiter-plate-based assay and absorbance values read using the Bioscreen C instrument (Labsystems, Espoo, Finland).

$P$. corrugata culture filtrates were added to freshly grown CV026 $\left(1 \times 10^{9} \mathrm{CFU} \mathrm{ml}{ }^{-1}\right)$ at a ratio of 1:10 to a final volume of $300 \mu \mathrm{l}$ (10 replicates for each cultural filtrate) and incubated in the Bioscreen $\mathrm{C}$ system for $16 \mathrm{~h}$ at $27^{\circ} \mathrm{C}$ with continuous shaking to allow induction of violacein formation. A 10-replicate lane loaded only with CV026 was also included. Turbidity at $600 \mathrm{~nm}$ was used for growth control. After incubation, the plates were dried at $60^{\circ} \mathrm{C}$ until all medium had evaporated (approximately $6 \mathrm{~h}$ or overnight). The violacein was resolubilized by adding $100 \mu \mathrm{l}$ of dimethyl sulfoxide to each well and incubating the plates in the Bioscreen $\mathrm{C}$ system for $2 \mathrm{~h}$ with continuous shaking. The amounts of violacein measured at 590 $\mathrm{nm}$ by adding the culture filtrates were used as an indirect measure of AHL production. These values were subtracted by those obtained in the wells inoculated only with CV026.

\section{In vitro bioassay for LDP production.}

Cultural filtrates of $P$. corrugata and mutant derivatives were evaluated for LDP production by a bioassay based on antimicrobial activity against $R$. pilimanae and Bacillus megaterium performed essentially as previously described (Cirvilleri et al. 2005). Antimicrobial activity was assessed by well-diffusion assay in plates containing solidified potato dextrose agar (PDA) (Oxoid) overlaid with $6 \mathrm{ml}$ of PDA added with $1 \mathrm{ml}$ of the test microrganism (approximately $10^{6} \mathrm{CFU} \mathrm{ml}^{-1}$ ). Wells, each $7 \mathrm{~mm}$ in diameter, were made in the agar using a cork borer, and $20 \mu \mathrm{l}$ of culture filtrate were transferred into each well. The plates were incubated up to 4 days at $27^{\circ} \mathrm{C}$, after which they were examined for clear inhibition zones around the well. Tests were carried out twice with triplicate wells each time.

\section{Plant inoculations.}

P. corrugata CFBP 5454 and the derivative mutants were tested for pathogenicity on tomato cv. Marmande plants grown in nursery flats, 1 month after germination. During the trials, plants were maintained in a growth chamber with a photoperiod of 16 and $8 \mathrm{~h}$ and $26^{\circ} \mathrm{C}$ temperature. Tomato plants were pin-prick inoculated on the stem at the axil of the first true leaf (20 plants per strain) with bacterial cells from a 48-h culture on NDA. After inoculation, plants were enclosed in polyethylene bags to maintain $100 \%$ relative humidity for 3 days; the bags were then removed until the end of the experiment. Ex- periments were performed at least twice. Host-pathogen interaction phenotype was evaluated approximately 10 days after inoculation using an empirical 0-to-4 increasing susceptibility scale based on the range of symptoms. Asymptomatic plants were scored as 0 ; score 1 was assigned to those plants showing only a dark discoloration along the pin puncture and was considered to be negative. Scores from 2 to 4 focused on symptom progressions and the presence of typical dark necrotic lesion within the stem (TPN): 2 , light discoloration of the stem $>5$ $\mathrm{mm}$; 3, typical TPN between 0.5 and $1 \mathrm{~cm} ; 4$, TPN $>1$. A point each was added if hollowing of the pith or presence of brown discoloration of the xylem beyond the TPN-affected areas were observed. Results were expressed as mean DI.

\section{ACKNOWLEDGMENTS}

This work was supported, in part, by a grant from the University of Catania 'Progetti di Ricerca d'Ateneo'. I. Bertani was supported by a fellowship from the Italian Cystic Fibrosis Research Foundation (Project FFC\#9/2007) with the contribution of the Delegazione FFC di Belluno.

\section{LITERATURE CITED}

Alexeyev, M. F. 1999. The pKNOCK series of broad-host-range mobilizable suicide vectors for gene knockout and targeted DNA insertion into the chromosome of gram-negative bacteria. BioTechniques 26:824-828.

Altschul, S. F., Gish, W., Miller, W., Myers, E. W., and Lipman, D. J. 1990. Basic local alignment search tool. J. Mol. Biol. 215:403-410.

Barnard, A. M. L., and Salmond, G. P. C. 2007. Quorum sensing in Erwinia species. Anal. Bioanal. Chem. 387:415-423.

Bender, C. L., Alarcon-Chaidez, F., and Gross, D.C. 1999. Pseudomonas syringae phytotoxins: Mode of action, regulation, and biosynthesis by peptide and polyketide synthetases. Microbiol. Mol. Biol. Rev. 63:266-292.

Better, M., Lewis, B., Corbin, D., Ditta, G., and Helinski, D. R. 1983. Structural relationships among Rhizobium meliloti symbiotic promoters. Cell 35:479-485.

Birnboim, H. C. 1983. A rapid alkaline extraction method for the isolation of plasmid DNA. Methods Enzymol. 100:243-255.

Carrol, N. B., Echandi, E., and Shoemaker, P. B. 1992. Pith necrosis of tomato in western North Carolina: Etiology and influence of cultural practices on its incidence and severity. Tech. Bull. N. C. Agric. Res. Serv. No. 300.

Catara, V. 2007. Pseudomonas corrugata: Plant pathogen and/or biological resource? Mol. Plant Pathol. 8:233-244.

Catara, V., Gardan, L., and Lopez, M. M.1997. Phenotypic heterogeneity of Pseudomonas corrugata strains from southern Italy. J. Appl. Microbiol. 83:576-586.

Catara, V., Sutra, L., Morineeau, A., Achouak, W., Christan, R., and Gardan, L. 2002. Phenotypic and genomic evidence for the revision of Pseudomonas corrugata and proposal of Pseudomonas mediterranea species sp. nov. Int. J. Syst. Evol. Microbiol. 52:1749-1758.

Choi, H. Y., Ryder, M. H., Gillings, M. R., Stokes, H. W., Ophel-Keller, K. M, and Veal, D. A. 2003. Survival of a lacZY-marked strain of Pseudomonas corrugata following a field release. FEMS (Fed. Eur. Microbiol. Soc.) Microbiol. Ecol. 43:367-374.

Chun, W., and Leary, J. V. 1989. Novel toxin produced by Pseudomonas corrugata, the casual agent of tomato pith necrosis. Page 93-116 in: Phytotoxins and Plant Pathogenesis. A. Graniti, R. D. Durbin, and A. Ballio, eds. Springer-Verlag, Berlin.

Cirvilleri, G., Bonaccorsi, A., Scuderi, G., and Scortichini, M. 2005. Potential biological control activity and genetic diversity of Pseudomonas syringae pv. syringae strains. J. Phytopathol. 153:654-666.

Cox, A. R. J., Thomson, N. R., Bycroft, B., Stewart, G. S. A. B., Williams, P., and Salmond, G. P. C. 1998. A pheromone-independent CarR protein controls carbapenem antibiotic synthesis in the opportunistic human pathogen Serratia marcescens. Microbiology 144:201-209.

Dulla, G., and Lindow, S. E. 2008. Quorum size of Pseudomonas syringae is small and dictated by water availability on the leaf surface. Proc. Natl. Acad. Sci. U.S.A. 105:3082-3087

Emanuele, M. C., Scaloni, A., Lavermicocca, P., Dalla Serra, M., Amodeo, P., Mannina, N., Vitale, R. M., Segre, A. L., Cruciani, O., Lodovichetti, F., Greco, M. L., Fiore, A., Gallo, M., D’Ambrosio, C., Coraiola, M., Menestrina, G., Graniti, A., and Fogliano V. 1998. Corpeptins, new bioactive lipodepsipeptides from cultures of Pseudomonas corrugata. FEMS (Fed. Eur. Microbiol. Soc.) Lett. 433:317-320.

Fernando, W. G. D., Ramarathnam, R., Krishnamoorthy, A. S., and Savchuk, 
S. C. 2005. Identification and use of potential bacterial organic antifungal volatiles in biocontrol. Soil Biol. Biochem. 37:955-964.

Fett, W. F., Cescutti, P., and Wijey, C. 1996. Exopolysaccharides of the plant pathogens Pseudomonas corrugata and Ps. flavescens and the saprophyte Ps. chlororaphis. J. Appl. Bacteriol. 81:181-187.

Figurski, D. H., and Helinski, D. R. 1979. Replication of an origin-containing derivative of plasmid RK2 dependent on a plasmid function provided in trans. Proc. Natl. Acad. Sci. U.S.A. 76:1648-1652.

Finney, A. H., Blick, R. J., Murakami, K. Ishihama, A., and Stevens, A. M. 2002. Role of the C-terminal domain of the alpha subunit of RNA polymerase in LuxR-dependent transcriptional activation of the lux operon during quorum sensing. J. Bacteriol. 184:4520-4528.

Fiori, M. 1992. A new bacterial disease of chrysanthemum: A stem rot by Pseudomonas corrugata Roberts et Scarlett. Phytopathol. Mediterr. 31:110-114.

Fuqua, C., and Greenberg, E. P. 2002. Listening in on bacteria: Acylhomoserine lactone signalling. Nat. Rev. Mol. Cell Biol. 3:685-695.

Fuqua, W. C., Winans, S. C., and Greenberg, E. P. 1994. Quorum sensing in bacteria: The LuxR-LuxI family of cell density responsive transcriptional regulators. J. Bacteriol. 176:269-275.

Fuqua, W. C., Winans, S. C., and Greenberg, E. P. 1996. Census and consensus in bacterial ecosystems: The LuxR-LuxI family of cell quorumsensing regulators. Annu. Rev. Microbiol. 50:727-751.

Garbeva, P., Voesenek, K., and Elsas, J. D. 2004. Quantitative detection and diversity of the pyrrolnitrin biosynthetic locus in soil under different treatments. Soil Biol. Biochem. 36:1453-1463.

Herrero, M., de Lorenzo, V., and Timmis, K. N. 1990. Transposon vectors containing non-antibiotic resistance selection markers for cloning and stable chromosomal insertions of foreign genes in gram-negative bacteria. J. Bacteriol. 172:6557-6567.

Kang, H., and Gross, D. C. 2005. Characterization of a resistance-nodulation-cell division transporter system associated with the syr-syp genomic island of Pseudomonas syringae pv. syringae. Appl. Environ. Microbiol. 71:5056-5065.

Kim, J., Kim, J. G., Kang, Y., Jang, J. Y., Jog, G. J., Lim, J. Y., Kim, S., Suga, H., Nagamatsu, T., and Hwang, I. 2004. Quorum sensing and the LysR-type transcriptional activator ToxR regulate toxoflavin biosynthesis and transport in Burkholderia glumae. Mol. Microbiol. 54:921-934.

Kovach, M. E., Elzer, P. H., Hill, D. S., Robertson, G. T., Farris, M. A., Roop II, R. M., and Peterson, K. M. 1995. Four new derivatives of the broad-host range cloning vector pBBR1MCS, carrying different antibiotic-resistance cassettes. Gene 166:175-176.

Licciardello, G., Bertani, I., Steindler, L., Bella, P., Venturi, V., and Catara, V. 2007. Pseudomonas corrugata contains a conserved $N$-acyl homoserine lactone quorum sensing system; Role in tomato pathogenicity. FEMS (Fed. Eur. Microbiol. Soc.) Microbiol. Ecol. 61:222-234.

Lopez, M. M., Rodriguez, F. R., Montojo, A. M., Salcedo, R. J., and Marti, E. R. J. 1988. Pepper, a new host of Pseudomonas corrugata. Page 88 in: (Abstr.) 5th Int. Congress Plant Pathol. International Society for Plant Pathology, Kyoto, Japan.

Lu, S. E., Scholz-Schroeder, B. K., and Gross, D. C. 2002. Characterization of the $s a l A, s y r F$, and $s y r G$ regulatory genes located at the right border of the syringomycin gene cluster of Pseudomonas syringae pv. syringae. Mol. Plant-Microbe Interact. 15:43-53.

Magyarosy, A. C., and Buchanan, B. B. 1995. First report of Pseudomonas corrugata causing pith necrosis on geraniums. (Abstr.) Phytopathology $85: 1040$.

Martinelli, D., Grossmann, G., Séquin, U., Brandl, H., and Bachofen, R. 2004. Effects of natural and chemically synthesized furanones on quorum sensing in Chromobacterium violaceum. BMC Microbiol. 4:25.

Miller, J. H. 1972. Experiments in Molecular Genetics. Cold Spring Harbor Laboratory, Cold Spring Harbor, NY, U.S.A.

Murakami, S., and A. Yamaguchi. 2003. Multidrug-exporting secondary transporters. Curr. Opin. Struct. Biol. 13:443-452.

Naumann, K., Griesbach, E., and Lattauschke, E. 1989. Occurrence and importance of bacterial stem pith necrosis of tomato in the GDR. Pages 473-478 in: Proc. 7th Int. Conf. Plant Pathol. Bacteria. Akademiai Kiadò, Budapest.

Parkinson, J. S., and Kofoid, E. C. 1992. Communication modules in bacterial signalling proteins. Annu. Rev. Genet. 26:71-112.

Quigley, N. B., Mo, Y. Y., and Gross, D. C. 1993. SyrD is required for syringomycin production by Pseudomonas syringae pathovar syringae and is related to a family of ATP-binding secretion proteins. Mol. Microbiol. 9:787-801.

Quinones, B., Pujol, C. J., and Lindow, S. E. 2004. Regulation of AHL production and its contribution to epiphytic fitness in Pseudomonas syringae. Mol. Plant-Microbe Interact. 17:521-531.

Quinones, B., Dulla, G., and Lindow, S. E. 2005. Quorum sensing regulates exopolysaccharide production, motility, and virulence in Pseudomonas syringae. Mol. Plant-Microbe Interact. 18:682-693.

Ramette, A., Moënne-Loccoz, Y., and Défago, G. 2003. Prevalence of fluorescents pseudomonads producing antifungal phloroglucinols and/or hydrogen cyanide in soils naturally suppressive or conductive to tobacco black root rot. FEMS (Fed. Eur. Microbiol. Soc.) Microbiol. Ecol. 44:35-43.

Risse, D., Beiderbeck, H., Taraz, K., Budzikiewicz, H., and Gustine, D. 1998. Corrugatin, a lipopeptide siderophore from Pseudomonas corrugata. Z. Naturforsch C. 53:295-304.

Saier, M. H., Jr, and Paulsen, I. T. 2001. Phylogeny of multidrug transporters. Semin. Cell. Dev. Biol. 12:205-213.

Sambrook, J., E. F. Fritsch, and T. Maniatis. 1989. Molecular Cloning: A Laboratory Manual, 2nd ed. Cold Spring Harbor Laboratory Press, Cold Spring Harbor, NY, U.S.A.

Scaloni, A., Dalla Serra, M., Amodeo, P., Mannina, L., Vitale, R. M., Segre, A. L., Cruciali, O., Lodovichetti, F., Greco, M. L., Fiore, A., Gallo, M., D'Ambrosio, C., Corniola, M., Minestrina, G., Graniti, A., and Fogliano V. 2004. Structure, conformation and biological activity of a novel lipodepsipeptide from Pseudomonas corrugata: Cormycin A. Biochem. J. 384:25-36

Scarlett, C. M., Fletcher, J. T., Roberts, P., and Lelliott, R. A. 1978. Tomato pith necrosis caused by Pseudomonas corrugata n. sp. Ann. Appl. Biol. 88:105-114.

Schmidt, C. S., Agostini, F., Leifert, C., Killham, K., and Mullins, C. E. 2004. Influence of inoculum density of the antagonistic bacteria Pseudomonas fluorescens and Pseudomonas corrugata on sugar beet seedling colonisation and suppression of Pythium damping off. Plant Soil 265:111-122.

Siverio, F., Cambra, M., Gorris, M. T., Corzo, J., and Lopez, M. M. 1993. Lypopolysaccharides as determinant of serological variability in $\mathrm{Pseu}$ domonas corrugata. Appl. Environ. Microbiol. 59:1805-1812.

Slater, H., Crow, M., Everson, L., and Salmond, G. P. C. 2003. Phosphate availability regulates biosynthesis of two antibiotics, prodigiosin and carbapenem, in Serratia via both quorum-sensing dependent and independent pathways. Mol. Microbiol. 47:303-320.

Spaink, P. H., Okker, R. J. H., Wijffelman, C. A., Pees, E., and Lugtenberg, B. J. J. 1987. Promoters in the nodulation region of the Rhizobium leguminosarum Sym plasmid pRL1JI. Plant Mol. Biol. 9:27-39.

Stachel, S., An, G., Flores, C., and Nester, E. 1985. A Tn3 lacZ transposon for the random generation of $\beta$-galactosidase gene fusions: Application to the analysis of gene expression in Agrobacterium. EMBO (Eur. Mol. Biol. Organ.) J. 4:891-898

Surico, G., Lavermicocca, P., and Iacobellis, N. S. 1988. Produzione di siringomicina e siringotossina in colture di Pseudomonas syringae py. syringae. Phytopathol. Mediterr. 27:163-168.

Sutra, L., Siverio, F., Lopez, M. M., Hanault, G., Bollet, C., and Gardan, L. 1997. Taxonomy of Pseudomonas strains isolated from tomato pith necrosis: Emended description of Pseudomonas corrugata and proposal of three unnamed fluorescent Pseudomonas genomo-species. Int. J. Syst. Bacteriol. 47:1020-1033.

von Bodman, S. B., and Farrand, S. K. 1995. Capsular polysaccharide biosynthesis and pathogenicity in Erwinia stewartii require induction by an $N$-acylhomoserine lactone autoinducer. J. Bacteriol. 177:5000-5008.

von Bodman, S. B., Majerczak, D. R., and Coplin, D. L. 1998. A negative regulator mediates quorum-sensing control of exopolysaccharide production in Pantoea stewartii subsp. stewartii. Proc. Natl. Acad. Sci. U.S.A. 95:7687-7692.

von Bodman, S. B., Bauer, W. D., and Coplin, D. L. 2003. Quorum sensing in plant-pathogenic bacteria. Annu. Rev. Phytopathol. 41:455-482.

Wang, N., Lu, S. E., Records, A. R., and Gross, D. C. 2006. Characterization of the transcriptional activators SalA and SyrF, which are required for syringomycin and syringopeptin production by Pseudomonas syringae pv. syringae. J. Bacteriol. 188:3290-3298.

Whitehead, N. A., Barnard, A. M., Slater, H., Simpson, N. J., and Salmond, G. P. 2001. Quorum-sensing in gram-negative bacteria. FEMS (Fed. Eur. Microbiol. Soc.) Microbiol. Rev. 25:365-404.

Zhang, L. H., Murphy, P. J., Kerr, A., and Tate, M. E. 1993. Agrobacterium conjugation and gene regulation by $\mathrm{N}$-acyl-L-homoserine lactones. $\mathrm{Na}-$ ture 362:446-448.

Zhou, T., and Paulitz, T. C. 1993. In vitro and in vivo effects of Pseudomonas spp. on Pythium aphanidermatum: Zoospore behavior in exudates and on the rhizoplane of bacteria-treated cucumber roots. Phytopathology 83:872-876. 